\title{
Rationale of fruit and berry raw materials choice to increase the confectionery nutritional value
}

\author{
Alla Bashta ${ }^{1}$, Nadija Ivchuk ${ }^{1}$, \\ Natalia Stetsenko ${ }^{1}$, Oleksandr Bashta ${ }^{2}$ \\ 1 - National University of Food Technologies, Kiev, Ukraine \\ 2 - National Aviation University, Kiev, Ukraine
}

Keywords:

Marmalade

Black cherry

Black currant

Plum

Bioflavonoids.

Article history:

Received

20.12.2020

Received in revised

form 19.03.2021

Accepted

16.07.2021

\section{Corresponding}

author:

Alla Bashta

E-mail:

alla.sher.b@

gmail.com

DOI:

$10.24263 / 2310-$

1008-2021-9-1-10

\section{Abstract}

Introduction. The aim of the study is to substantiate the choice of fruit and berry raw materials with high content of biologically active substances and to obtain a composition based on it to increase the confectionery nutritional value.

Materials and methods. Both traditional and nontraditional raw materials for marmalade production were studied: apples, plums, cherries, black currants, red currants, blueberries, cranberries, blackberries, sloe, viburnum, figs, gooseberries, goji berry, elderberry, black cherry, physalis. Using standard methods in each raw material determined the content of organic acids and pectic substances, both important and significant for marmalade production and the content of bioflavonoids, ascorbic acid, carotenoids and fiber, necessary to give the finished product health properties.

Results and discussion. It is advisable not only to expand the raw material base of the puree, but also to create blended compositions of puree for marmalade in order to increasing the nutritional value of the product, giving it health properties and creating competitive products on the market.

According to the established content in the studied cultivated and wild raw materials main biocomponents the following fruits and berries were selected: plum, black cherry and black currant.

The content of bioflavonoids, carotenoids and ascorbic acid is one of the highest in the selected berries of currant and black cherry among the studied samples at the same time with a high content of pectin $1.1 \%$, fiber and organic acids. At the same time the plum was chosen as a significant source of pectin and organic acids, which are important for jellification.

Using of a chosen fruit and berry puree composition in the amount of $25-30 \%$ as part of the finished marmalade allows enriching it with a significant amount of biologically active substances, the content of which in a traditional product is insignificant.

Conclusions. The results showed the suitability of fruit and berry raw materials, including non-traditional wild, involving in the manufacturing of health products. 


\section{Introduction}

Sugar confectionery, in particular the pastille-marmalade group, is in great demand among the world, especially children, due to its pleasant taste and appearance. However, unfortunately, this is most often achieved through the use of synthetic coloring agents and flavors, which do not have a positive effect, and in some cases their consumption has a negative effect on the human body $[1,2]$.

Currently, the world market does not have a wide range of herbal supplements from fruit and non-traditional officinal-technical raw materials (purees, pastes, concentrated juices, powders), which can be used to increase the biological value of jelly marmalade and as coloring agents $[2,8]$. In addition, most of these additives involve strict technological processing of raw materials, during which coloring materials and nutrients are lost: vitamins, dietary fiber, organic acids, glycosides, etc. [6,7].

The authors $[21,22]$ note that among plant additives, those with high coloring ability stand out.

Fruit and berry marmalade is of special value in the group of marmalade products [13, 23]. However, its production involves the use of apple puree, which is the main raw material of recipes and high requirements for it. The balance of acidity, water-soluble pectin content, its gelling ability allows to choose only certain varieties of apples for the production of puree. The decline of agriculture, the food-canning industry, significantly reduced the volume of apple puree with high gelling ability, which naturally affected the production of fruit and berry marmalade.

The use of purees of other fruits and berries in traditional marmalade technologies is quite limited [14]. Plum and apricot were used for the production of jelly drops, other species in very small quantities - as additional flavoring raw materials to expand the range [12,17].

In the world market, marmalade products are mainly represented by jelly marmalade $[27,28]$. Fruit and jelly marmalade occupies an intermediate position between the more scarce and useful fruit and berry and common jelly marmalade. By definition, it is made on the basis of gelling agents in combination with gelling fruit and berry puree.

It has already been noted that a number of authors [17,25] aim to obtain confectionery products for health purposes, adjusting their chemical composition by using non-traditional raw materials suitable for the production of this products.

Thus, it is important to develop new types of these products using natural plant ingredients in order to expand the range, increase the biological value and create competitive products in the market.

The aim of the study is to substantiate the choice of fruit and berry raw materials with high content of biologically active substances and to obtain a composition based on it to increase the confectionery nutritional value.

\section{Materials and methods}

\section{Fruit and berry raw materials}

The subject of research is both traditional and non-traditional for the production of marmalade raw materials: apples, plums, cherries, black currants, red currants, blueberries, cranberries, blackberries, sloe, viburnum, figs, gooseberries, goji berry, elderberry, black cherry, physalis, fruit and berry puree, fruit and jelly marmalade for health purposes. 
Using standard methods [29-31] in each of the raw materials types the main biocomponents content required for the production of health marmalade was determined.

\section{Determination of pectin content}

The content of pectin was determined by the weight method, which is based on determining the mass fraction of pectic acid by the mass amount of calcium pectate formed by the interaction under certain conditions of calcium chloride with pectic acid [32-35].

\section{Determination of fiber content}

Determination of the mass fraction of fiber is based on the decomposition of all other organic substances with concentrated nitric acid in a mixture with acetic and trichloracetic acids [32-33].

\section{Determination of bioflavonoids content}

The study of the total content of bioflavonoids in fruit and berry raw materials using Folin-Ciocalteu reagent and determination of the content of flavonols $(\mathrm{mg} / 100 \mathrm{~g}$, in terms of rutin), anthocyanins by standard methodology of spectrophotometric method in the finished marmalade [31, 36, 37, 39].

\section{Determination of carotenoids content}

Quantitative content of carotenoids is determined by known spectrophotometric method $[31,39-41]$.

\section{Determination of organic acid content}

The organic acid content was determined by iodometric method, which is based on the reaction of sodium thiosulfate with iodine released by the interaction of free organic acids with a neutral solution of potassium iodide-iodate [31, 39-41].

\section{Determination of organic acid content}

Vitamin C content was determined using sodium 2,6-dichlorophenolindophenolate [31, 39-41].

\section{Determination of sensory, physicochemical and rheological parameters of marmalade masses}

The Reotest- 2 device was used to study the change in the viscosity of marmalade masses in the process of marmalade boiling and selection of the optimal amount of fruit and berry raw materials. The shape, appearance, texture, fracture appearance, color, taste and smell of marmalade were determined sensoryally. Humidity, mass fraction of reducing substances, total acidity, mass fraction of ash were determined by methods of physicochemical analysis [29-31, 42]. 


\section{Results and discussion}

\section{Obtaining a fruit and berry mix with a high content of biologically active substances, the most suitable for making marmalade}

Marmalade products are dietary products due to the presence in their composition of gelling substances capable of removing heavy metal ions and radioactive ions from the body. However, the health effect of these products can be enhanced by the use in the technology of their production of fruits and berries, including wild, with predetermined healing properties $[15,18]$.

To evaluate fruit and berry crops that are the most suitable in marmalade production technologies, both cultivated and wild raw materials were studied: apples, plums, cherries, black currants, red currants, blueberries, cranberries, blackberries, sloe, viburnum, figs, gooseberries, goji berry, elderberry, black cherry, physalis. All these cultures are widespread in the Central and West Europe and have long been used in the diets of the population, as well as in folk and official medicine for the prevention and therapy of non-specific diseases $[5,6]$.

In our opinion, the choice of plant materials should be based on quantitative and qualitative ratios of a complex of biologically active substances synthesized in them by nature, sensory and technological properties of fruit and berry raw materials puree samples, most suitable for making marmalade.

According to the literature data $[2,18,20]$.at approximately the same $\mathrm{pH}$ values for some samples of puree, the total acidity varies significantly. This is probably due to the high values of both organic acids in the chemical composition and other acid-reactive substances. This should be taken into account when creating blends of puree to ensure the gelling ability of the mixture, as well as taste, perhaps even without the addition of acids [18].

However, important and decisive for marmalade production from a technological point of view is the quantity and quality of pectin in the puree [38].

According to the technological tasks, for the formation of the jelly-like structure of marmalade there is a need to add to the system an additional amount of structurant [27, 42]. In addition to valuable technical properties, the range of their biological action is wide. Many pectins have an immunomodulatory effect and are able to remove heavy metals, biogenic toxins, xenobiotics, and metabolic products from the body.

Taking into account the above considerations, we determined these indicators in the raw material, summarized in Table 1.

Pectic substances are contained in all pods and berries (Table 1). Especially many of them in apples, black currants, cherries, gooseberries, black cherry. Also, a high content of organic acids is expected in all tested samples.

The importance of biocomponents in the composition of fresh raw materials, and in the obtained puree from them, is confirmed both by the technological suitability of this raw material and by clarification their role in the functioning of the human body [5].

An integral characteristic of fruit products intended for both fresh consumption and production of semi-finished and finished products is the amount of biologically active substances, including p-active substances, carotenoids, dietary fiber and ascorbic acid [43, 44]. 
Experimental data to determine the content of dry matter, pectin and organic acid $100 \mathrm{~g}$ of raw materials as the main indicators that directly affect the production of marmalade

\begin{tabular}{|l|c|c|c|}
\hline Test samples & Solids/\% & Pectic substances/\% & Organic acids/\% \\
\hline Apples & 15.3 & 1.3 & 0.9 \\
\hline Cherries & 14.5 & 1.0 & 0.8 \\
\hline Cherry & 14.0 & 0.8 & 1.2 \\
\hline Plum & 14.6 & 1.2 & 2.0 \\
\hline Black currant & 13.5 & 1.1 & 1.8 \\
\hline Red currant & 13.2 & 0.6 & 2.2 \\
\hline Blueberries & 13.0 & 0.3 & 0.9 \\
\hline Cranberry & 11.2 & 0.7 & 3.1 \\
\hline Sloe & 17.3 & 0.9 & 2.8 \\
\hline Gooseberries & 15.0 & 1.0 & 3.1 \\
\hline Figs & 19.2 & 0.7 & 0.6 \\
\hline Blackberries & 13.6 & 0.5 & 1.4 \\
\hline Viburnum & 14.0 & 0.8 & 1.2 \\
\hline Goji berry & 17.7 & 0.4 & 1.8 \\
\hline Elderberry & 16.4 & 0.9 & 1.6 \\
\hline Black cherry & 15.9 & 1.1 & 1.9 \\
\hline Physalis & 10.2 & 0.9 & 1.2 \\
\hline
\end{tabular}

$\mathrm{n}=3 ; \mathrm{p}>0.95$

Polyphenolic compounds are involved in redox reactions, respiration, nucleic acid formation and amino acid metabolism, protein synthesis, improve carbohydrate absorption. In addition, they normalize cholesterol metabolism, prevent the accumulation of harmful free radicals in body tissues, increase its resistance to infectious diseases and adverse external actions that cause overheating, hypothermia and oxygen deficiency, and human performance.

Bioflavonoids have a wide range of biological effects due to anti-allergenic, anticarcinogenic, anti-inflammatory and antioxidant properties. These compounds contained in fruits and berries are able to remove alkaloid salts and heavy metals from the body and are characterized by antiviral and disinfectant effects. In combination with vitamin $\mathrm{C}$, bioflavonoids allow to avoid many diseases, normalize the permeability of capillaries, maintain the elasticity of the walls and reduce the likelihood of internal hemorrhage $[45,46]$.

Carotenoids have anti-inflammatory and wound-healing properties, they regulate metabolic processes, act as photo protectors and antioxidants, prevent mutagenesis and carcinogenesis at the molecular and cellular levels, show radio protective activity and have a positive effect during pathogenic conditions caused by radioactive substances; effective in the treatment of xerophthalmia, improve fertility, growth and development of the young organism. Individual carotenoids (zeaxanthin and lutein) are an integral part of the retina and lens of the eye. Epidemiological studies have shown a direct dependence of the risk of agerelated retinal degeneration and cataracts on the content of these carotenoids in the serum and disorders of their intake with food [47].

Fiber improves digestion, stimulates peristalsis, increases the rate of passage of food through the digestive tract, absorbs fats, toxins and mucus from the stomach and intestines and increases the absorption of nutrients. Fiber frees from toxins not only the digestive tract 
but also the lymphatic system [33, 48].

These biologically active substances are important for the normal functioning of the body. Taking into account the above considerations on the relevance of use of non-traditional raw materials, especially rich in natural colorants, in the production of marmalade, identified these biocomponents, summarized in Table 2.

Analyzing Table 2, we can conclude that each type of fruit or berry has its own valuable biologically active substances, with which food products can be enriched. It is advisable not only to spread the raw material base of non-traditional raw materials, but also to create blended mixtures for marmalade in order to ensure its more valuable content of biologically active substances.

Table 2

Experimental data for determining the content of the main valuable biocomponents of traditional and non-traditional fruit and berry raw materials

\begin{tabular}{|c|c|c|c|c|}
\hline Test samples & $\begin{array}{c}\text { Bioflavonoids } \\
/ \mathrm{mg} \%\end{array}$ & \begin{tabular}{|c|} 
Carotenoids \\
$/ \mathrm{mg} \%$
\end{tabular} & $\begin{array}{c}\text { Vitamin C } \\
/ \mathrm{mg} \%\end{array}$ & $\begin{array}{c}\text { Fiber, } \\
\%\end{array}$ \\
\hline Apples & 117 & $\begin{array}{l}0.7 \\
\end{array}$ & 20 & 0.6 \\
\hline Cherries & 1283 & 2.8 & 63 & 0.3 \\
\hline Cherry & 1300 & 2.6 & 65 & 0.5 \\
\hline Plum & 630 & 3.6 & 18 & 0.5 \\
\hline Black currant & 1840 & 3.9 & 201 & 3.0 \\
\hline Red currant & 1276 & 3.2 & 52 & 2.5 \\
\hline Blueberries & 1985 & 1.3 & 57 & 2.6 \\
\hline Cranberry & 975 & 0.9 & 34 & 2.0 \\
\hline Sloe & 810 & 1.6 & 35 & 1.3 \\
\hline Gooseberries & 829 & 3.1 & 61 & 2.0 \\
\hline Figs & 347 & 2.0 & 10 & 2.7 \\
\hline Blackberries & 2512 & 2.7 & 63 & 2.4 \\
\hline Viburnum & 1328 & 2.4 & 42 & 1.9 \\
\hline Goji berry & 1625 & 3.9 & 70 & 4.4 \\
\hline Elderberry & 2379 & 1.5 & 59 & 3.7 \\
\hline Black cherry & 2387 & 4.5 & 64 & 3.4 \\
\hline Physalis & 796 & 0.8 & 54 & 1.9 \\
\hline
\end{tabular}

$\mathrm{n}=3 ; \mathrm{p}>0.95$

Analysis and comparison of the data in Table 1 and Table 2 makes it possible to characterize each culture in terms of compliance with the next factors, namely to enrich the finished marmalade with bioactive substances of selected raw materials, while choosing the raw material that is most suitable for marmalade production. The studied cultivated varieties and wild species have a high content of certain biologically active substances: bioflavonoids, carotenoids, ascorbic acid and fiber. For some types of raw materials there is a correlation between the high content of biologically active substances in Table 1 and Table 2.

Apples, with a high content of pectin, balanced acidity and good gelling ability are traditionally used for the marmalade production $[18,26]$. The selection of our samples was based on the choice of those fruits and berries that primarily have a high content of pectin, organic acids and colorants with a high content of all other specified and identified 
biocomponents in Table 2. Our task was to select the plant raw materials, both rich in these biologically active substances, and the most suitable for the marmalade manufacturing. The following fruits and berries were selected according to the established and determined indicators: plum, black cherry and black currant. They have a high content of pectin and organic acids (Table 1). The following raw materials have a high content of bioflavonoids: blackberries, black currant, goji berry, black cherry, blueberry (Table 2).

Pectin content of blueberries, goji berries and blackberries is in the range of $0.3-0.6 \%$. And the content of bioflavonoids, carotenoids and ascorbic acid (Table 2) is one of the highest in selected berries of currants and black cherries with a high content of pectin $1.1 \%$, fiber and organic acids. The plum was chosen as a significant source of pectin and organic acids.

\section{Obtaining fruit and jelly marmalade for health purposes on the basis of fruit and berry mix using unconventional raw materials}

Fruit and jelly marmalade is obtained by traditional boiling of fruit purees, fruits, berries with sugar. In addition, pectin is used as a gelling base [26].

As functional enrichments for the marmalade production in this paper, it is proposed to use puree of plum, black currant and black cherry, selected from previous studies.

The puree was obtained by traditional technology [25-27], which includes the following steps: washing, inspection, steaming 3-8 min or blanching in water, pulping in a double pulping machine with sieves having holes of $1.5,2.0$ and $0.4-0.8 \mathrm{~mm}$, the pulp was preserved by pasteurization at a temperature of $85{ }^{\circ} \mathrm{C}$, as the most economical. This temperature promotes the preservation of labile substances, ensures the destruction of pathogenic vegetative microorganisms and allows obtaining a microbiologically safe product. Preservation of bioflavonoids is greatly enhanced by ascorbic acid, as polyphenols are able to suppress the action of ascorbotase, blocking copper in its composition, thereby slowing the oxidation of ascorbic acid, which has a stabilizing effect on bioflavonoids [44].

The obtained puree fully complied with the standards, and on their basis created a blend for later use for the production of fruit and jelly marmalade. It is established that to create a composition of fruit and berry mix, the optimal recipe ratio will be a ratio of 1:1:1 (puree of black currant, plum and black cherry, respectively).

Selected purees in certain quantities harmoniously complement each other's sensory properties, creating a functional enrichment with an original taste and pleasant aroma and a significant content of biologically active substances.

Subsequently, this ratio of the composite mixture was used to obtain marmalade.

The positive effect of marmalade depends on the mutual complex influence of all components and their quantity $[10,46]$. The ratio of the ingredient's composition is selected experimentally to ensure in the finished marmalade a high content of biologically active compounds inherent of its composition in raw materials. For this purpose, marmalade with a different percentage of fruit and berry puree addition, from 10 to $40 \%$, was obtained.

The finished product had a pleasant smell and taste, attractive color when added to marmalade puree in the amount of $10-30 \%$. When applying the composition of more than $30 \%$, the color of the finished product is deep purple, unattractive to the consumer color and sour taste. Besides, the addition of the mix in an amount of more than $30 \%$, leads to a weakening of the structure of the finished product, due to the sugar reduction in the recipe (less than 60\%).

Therefore, the addition of a fruit and berry puree composition in the amount of $25-30 \%$ allows you to enrich the finished product with functional ingredients, as well as give it an attractive color. 
During the fruit and jelly marmalade production, the recipe mixture together with the gelling agent contains white sugar, syrup, citric acid and fruit and berry puree. Since pectin is used as a gelling agent for the production of the developed marmalade, two main factors are needed to create optimal conditions for gelling - the content of a significant amount of sugar and an acidic environment [27, 42].

The first condition is fulfilled by introducing a significant amount of sugar into the recipe mixture. To create an environment with a low $\mathrm{pH}$ value in the industrial manufacturing of marmalade products the mixing in organic acids into the marmalade mass there is used. The practical norm of acid, in terms of malic acid, with a pectin content in the boiling mass of $0.8-1.0 \%$ and sugar content of $60-70 \%$ in the marmalade product is $0.8 \%$ [42].

We have made an assumption that it is possible to create an environment of low $\mathrm{pH}$ by using our chosen composition of fruit and berry mix, which contains a significant amount of free organic acids (Table 1).

The content of organic acids in the boiled marmalade mass was determined using apple pectin powder $1.0-1.3 \%$ and sugar $60-65 \%$, syrup $5-7 \%$ and $25-30 \%$ of the fruit and berry mix composition. It was determined that the content of organic acids in the boiled marmalade mass is $0.8-0.9 \%$ and allows for normal jellification.

Thus the ratio of components in mass fractions: sugar $60-65 \%$, the selected fruit and berry mix $25-30 \%$, syrup $5-7 \%$ and pectin $1-1.3 \%$ allow obtaining the finished product of the desired jelly-like consistency with a dry surface and fine crystalline crust.

The main physicochemical (Table 3) and sensory parameters (Table 4) of the finished health marmalade were studied.

Table 3

Research of the basic physical and chemical indicators of a finished product

\begin{tabular}{|c|c|c|c|c|c|c|}
\hline \multirow{2}{*}{$\begin{array}{c}\text { Product } \\
\text { name }\end{array}$} & \multicolumn{2}{|c|}{ Humidity/\% } & \multicolumn{2}{c|}{$\begin{array}{c}\text { Weight part of } \\
\text { sugars/\% }\end{array}$} & \multicolumn{2}{c|}{ Total acidity/deg } \\
\cline { 2 - 7 } & Norm & Experiment & Norm & Experiment & Norm & Experiment \\
\hline $\begin{array}{c}\text { Fruit and jelly } \\
\text { marmalade }\end{array}$ & $\begin{array}{c}15- \\
24\end{array}$ & 21.3 & $\begin{array}{c}\text { Not } \\
\text { more } \\
25\end{array}$ & 21 & $\begin{array}{c}7.5- \\
22.5\end{array}$ & 9.7 \\
\hline
\end{tabular}

The values of the main physicochemical parameters are obtained within normal range [42].

The sensory characteristics of the developed marmalade were analyzed (Table 4).

It is important that for the production of marmalade for health purposes there are used vegetable raw materials, which contain a significant amount of bioflavonoids, which are able to interrupt the chains of free radical oxidation reactions, i.e. have a powerful antioxidant effect. These substances help to protect cell membranes from potentially harmful effects or reactions that can be caused by excessive oxidation in the body, as well as prevent dysfunction of cell membranes, deterioration of health and premature aging [31, 45].

Undoubtedly that the plant-based materials present in the recipe of marmalade enriches the finished product with a significant amount of phenolic compounds, but they can be destroyed, as they are sensitive to any changes during the manufacturing process [29, 43]. 


\section{Sensory characteristics of the obtained marmalade}

\begin{tabular}{|l|l|}
\hline Indicator name & \multicolumn{1}{|c|}{ Characteristic } \\
\hline Taste and smell & $\begin{array}{l}\text { Explicitly expressed. Specific to the raw materials from which this } \\
\text { marmalade is made }\end{array}$ \\
\hline Color & $\begin{array}{l}\text { Smooth, homogeneous, purple. Specific to the raw material from } \\
\text { which this marmalade is made }\end{array}$ \\
\hline Consistence & Jelly-like \\
\hline Form & Correct, without deformations \\
\hline Surface & $\begin{array}{l}\text { Dry, not sticky, with a fine crystalline crust or sprinkled with } \\
\text { granulated sugar }\end{array}$ \\
\hline
\end{tabular}

Analysis of polyphenolic compounds content of the considered food systems was performed on the absorption spectra in the ultraviolet and visible regions of the spectrum. $10 \%$ ethanol extracts of marmalades: fruit and jelly, prepared using the proposed fruit and berry mix of plum, black currant and black cherry puree, and jelly - using only pectin as a gelling agent were prepared for this purpose. A spectrophotometer SF-26 was used to analyze the selected samples at the following values of wavelength. Catechins were determined at wavelengths of 250-290 nm, flavonol glycosides were determined at wavelengths of 320$360 \mathrm{~nm}$, anthocyanins were determined at wavelengths of 520-560 nm.

The obtained results showed that the marmalade with the addition of fruit and berry mix compositions has a higher optical density.

According to the obtained data, the effect of marmalade enrichment with catechins, flavonols and anthocyanins was calculated. The results are shown in Table 5.

Table 5

Results of the obtained marmalade enrichment with catechins, flavones and anthocyanins

\begin{tabular}{|c|c|c|c|}
\hline Original pectin based jelly marmalade & \multicolumn{3}{|c|}{ Enrichment effect/\% } \\
\cline { 2 - 4 } (without the fruit or berry puree use) & Catechins & Flavonols & Anthocyanins \\
\hline $\begin{array}{c}\text { The original marmalade, enriched with a } \\
\text { composition of fruit and berry mix of plum } \\
\text { puree, black currant and black cherry }\end{array}$ & 12.74 & 28.65 & 80.05 \\
\hline
\end{tabular}

Thus, the use of the fruit and berry mix composition can significantly increase the content of phenolic compounds (catechins, flavonols and anthocyanins) in the finished product, which gives it new health properties.

\section{Conclusions}

1. Feasibility of new non-traditional raw materials using for the production of fruit and jelly marmalade, which allows expanding the range of marmalade products and the range of confectionery for health purposes is investigated and confirmed in this paper.

2. The use of raw materials, specifically the fruit and berry mix based on plum, black 
currant and black cherry, in the technology of marmalade, allows enriching it with a significant amount of biologically active substances, the content of which in a traditional product is negligible.

3. Plant enrichment apolymeric flavonoid forms are able to quench radical reactions in the body and they better combined with carbohydrate products. Simple sugars immediately enter the bloodstream and bring antioxidants from plant materials.

\section{References}

1. Sicari V., Pellicanò T.M., Laganà V., Poiana M. (2018), Use of orange by-products (dry peel) as an alternative gelling agent for marmalade production: evaluation of antioxidant activity and inhibition of hmf formation during different storage temperature, J. Food Process. Preser,42, e13429.

2. Artamonova M.V., Lysyuk G.M., Tuz N.F., editors (2015), Technology of jelly marmalade with the use of cryospores of plant origin, KhSUFT, Kharkiv.

3. Ajala A.S., Ajao A.I. (2012), Production and quality evaluation of ginger-flavoured banana marmalade, International Journal of Emerging trends in Engineering and Development, 7, pp. 579-584.

4. Matheus Henrique Mariz de Avelar, Guilherme de Castilho Queiroz, Priscilla Efraim. (2020), Sustainable performance of cold-set gelation in the confectionery manufacturing and its effects on perception of sensory quality of jelly candies, Cleaner Engineering and Technology, 1, p. 00005.

5. Vendrame S., Del Bo' C., Ciappellano S., Riso P., Klimis-Zacas D. (2016), Berry fruit consumption and metabolic syndrome, Antioxidants, 5(4), p. 34.

6. Beattie J., Crozier A., Duthie G.G. (2005), Potential health benefits of berries, Current Nutrition \& Food Science, 1, 71.

7. Jenkins D.J., Nguyen T.H., Kendall C.W., Faulkner D.A., Bashyam B., Kim I.J., Ireland C., Patel D., Vidgen E., Josse A.R., Sesso H.D., Burton-Freeman B., Josse R.G., Leiter L.A., Singer W. (2008), The effect of strawberries in a cholesterol-lowering dietary portfolio, Metabolism, 57(12), pp. 1636-1644.

8. Szajdek A., Borowska E.J. (2008), Bioactive compounds and health-promoting properties of berry fruits: A review, Plant Foods and Human Nutrition, 63(4), pp. 147-156.

9. García-Martínez E., Ruiz-Diaz G., Martínez-Monzó J., Camacho M.M., Martínez-Navarrete N., Chiralt A. (2002), Jam manufacture with osmode hydrated fruit, Food Research International, 35(2-3), pp. 301-306.

10. Sourav Garg, Payel Ghosh, Sandeep Singh Rana, Rama Chandra Pradhan. (2019), Preparation and quality evaluation of nutritionally enriched jam made from blends of indian blackberry and other fruits, International Journal of Fruit Science, 19(1), pp. 29-44.

11. Yong Kang Cheah, Mohd Azahadi, Noor Safiza Mohamad Nor, Siew Nooi Phang, Noor Hazilah Abd Manaf. (2020), Sociodemographic factors associated with consumption of confectionery among obese and non-obese adults: A secondary analysis, Obesity Research \& Clinical Practice, 14(5), pp. 428-436.

12. Toktam Mohammadi-Moghaddam, Ali Firoozzare, Samin Daryadar, Zahra Rahmani. (2020), Black plum peel jam: physicochemical properties, sensory attributes, and antioxidant capacity, International Journal of Food Properties, 23(1), pp. 1737-1747.

13. Pramanick P., Zaman S., Mitra A. (2014), Processing of fruits with special reference to S. Apetala fruit jelly preparation, International Journal of Universal Pharmacy and Bio Sciences, 3(5), pp. 36-49.

14. Emaldi U., Nassar J., Semprum C. (2006), Cardondato (Stenocereusgriseus, Cactaceae) fruit pulp as raw material for marmalade production, Archivos latinoamericanos de 
nutrición, 56(1), pp. 83-90.

15. Skoczyñska A., Jêdrychowska I., Porêba R., Affelska-Jercha A., Turczyn B., Wojakowska A., Andrzejak R. (2007), Influence of chokeberry juice on arterial blood pressure and lipid parameters in men with mild hypercholesterolemia, Pharmacol. Rep., 59, pp. 177-182.

16. Kardum N., Petrovi'c-Oggiano G., Takic M., Glibeti'c N., Zec M., Debeljak-Martacic J., Koni'c-Risti'c A. (2014), Effects of glucomannan-enriched, aronia juice-based supplement on cellular antioxidant enzymes and membrane lipid status in subjects with abdominal obesity, The Scientific World Journal, 869250.

17. Quaranta H.O., Eterović J.E., Piccini J.L. (1986), Essential elements in fresh and irradiated strawberries and strawberry marmalade, International Journal of Radiation Applications and Instrumentation. Part A. Applied Radiation and Isotopes, 37(7), pp. 633-634.

18. Shmatchenko N., Artamonova M., Aksonova O., Oliinyk S. (2018), Investigation of the properties of marmalade with plant cryoadditives during storage, Food Science and Technology, 12(1).

19. Kolmakova N.S. (2008), Recent research on the safety of synthetic dyes and market trends, Food industry, 1, pp. 56-57.

20. Dohadwala M.M., Holbrook M., Hamburg N.M., Shenouda S.M., Chung W.B., Titas M., Kluge M.A., Wang N., Palmisano J., Milbury P.E., et al. (2011), Effects of cranberry juice consumption on vascular function in patients with coronary artery disease, Am. J. Clin. Nutr.,93, pp. 934-940.

21. Zanotti I., Dall'Asta M., Mena P., Mele L., Bruni R., Ray S., Del Rio D. (2015), Atheroprotective effects of (poly)phenols: A focus on cell cholesterol metabolism, Food Funct., 6, pp. 13-31.

22. Manganaris G.A., Goulas V., Vicente A.R., Terry L.A. (2014), Berry antioxidants: Small fruits providing large benefits, J. Sci. Food Agric., 94, pp. 825-833.

23. Fil M., Mikhailyuk O. (2017), Innovative approach technologies fruit marmalade, Scientific Messenger of LNU of Veterinary Medicine and Biotechnologies. Series: Food Technologies, 19(75), pp. 55-58.

24. Savaş E., Tavşanl H., Çatalkaya G., Çapanoğlu E., Tamer C.E. (2020), The antimicrobial and antioxidant properties of garagurt: Traditional Cornelian cherry (Cornus mas) marmalade, Quality Assurance and Safety of Crops \& Foods, 12(2), pp. 12-23.

25. Lilian E. Figueroa, Diego B. Genovese. (2019), Fruit jellies enriched with dietary fibre: Development and characterization of a novel functional food product, $L W T$ - Food Science and Technology, 111, pp. 423-428.

26. Bashta A., Leschinska T. (2013), Developing a method of obtaining fruit jelly marmalade for recreational purposes, Scientific works of NUFT, 53, pp. 63-70.

27. Tsuglenok N.V., et al. (2014), Technology for the production of jelly marmalade based on red currant pectin with the addition of natural dye, KrassGAU Bulletin, 8, pp. 213-219.

28. Magomedov G.O., et al. (2013), Jelly marmalade based on natural honey. Confectionery production, 3, pp. 10-12.

29. Escarpa A., González M.C., López M.Á., editors (2015), Agricultural and Food Electroanalysis, John Wiley \& Sons, Ltd.

30. Kanter V.M., Matison V.A., Fomenko M.A., et al. (2003), Basic methods of sensory evaluation of foodstuffs, Food Industry, 10, pp. 6-13.

31. Kondratenko P.V., Shevchuk L.M., Levchuk L.M. (2008), Methods of quality assessment of fruit and berry products, SPD "Zhyteliev SI”, Kyiv.

32. Skorobohatyi Ya, Fedorko V. (2005), Chemistry and methods of research of raw materials, Kompakt, Lviv.

33. Bashta A., Ivchuk N., Bashta O. (2015), Yacón and Scorzonera as functional enrichment of food, Ukrainian Journal of Food Science, 3(1), pp. 13-22.

34. Chelyabieva V.M., Siza O.I., Savchenko O.M. (2018), Obtaining pectin from currant 
pomace for the production of marshmallows based on gooseberry puree, Progressive techniques and technologies of food production of restaurants and trade, 1, pp. 303-317.

35. Doesburg J.J. (1965), Pectic substances in fresh and preserved fruits and vegetables, I.B.V.T.-communaction Nr. 25, Wageningen.

36. Labanova A.A., Budaeva V.V., Sakovich G.V. (2004), Research of biologically active flavonoids in plant extracts, Chemistry of plant raw materials, 1, pp. 47-52.

37. Korulkin D.Yu., Abilov J.A., Muzychkina R.A., Tolstikov G.A. (2007), Natural flavonoids, Teo, Novosibirsk.

38. Gramza-Michałowska A., Bueschke M., Kulczyński B., et al. (2019), Phenolic compounds and multivariate analysis of antiradical properties of red fruits, J. of Food Measurement and Characterization, 13(3), pp. 1739-1747.

39. Ermakov A.I., Arasimovich V.V., Yarosh N.P. (1987), Methods of biochemical research of plants, Agropromizdat, Moscow.

40. Vishnikin A., Melnikov K., Kolisnychenko T., Lystopad T., Pidhorna D. (2019), Development of berry drinks with a high content of ascorbic acid, Food Science and Technology, 13(3).

41. Malyugina E.A., et al. (2013), The study of the carotenoid content in the inflorescences of the spreading marigold, Current issues in pharmacy and medicine: science and practice, 3. pp. 89-91.

42. Lurie I.S. (1978), Guidelines for technochemical control in the confectionery industry, Food industry, Moscow.

43. Shevchuk L.M. (2019), Content of biologically active agents in fruits of traditional and rare in crop fruit grades, Bulletin of Agricultural Science, 11(800), pp. 81-88.

44. Saura-Calixto F., Serrano J., Goni I. (2007), Intake and bioaccessibility of total polyphenols in a whole diet, Food Chem, 101, pp. 492-501.

45. Scalbert A., Manach C., Morand C., Remesy C. (2005), Dietary polyphenols and the prevention of diseases, Crit. Rev. Food Sci. Nutrition, 45, pp. 1-20.

46. Battino M., Beekwilder J., Denoyes-Rothan B., Laimer M., McDougall G.J., Mezzetti B. (2009), Bioactive compounds in berries relevant to human health, Nutrition Reviews, 67(1). pp. $145-150$.

47. Bunea A. (2008), Lutein Esters from Tageteserecta L.: Isolation and enzymatic hydrolysis, Bulletin UASVM Animal Science and Byotechnologies, 65(1-2), pp. 410-413.

48. Jun Liu, Stefan Willför, Chunlin Xu. (2015), A review of bioactive plant polysaccharides: Biological activities, functionalization, and biomedical applications, Bioactive Carbohydrates and Dietary Fibre, 5(1), pp. 31-61. 